\title{
O CONHECIMENTO DO NUTRICIONISTA FRENTE AO PACIENTE OBESO MÓRBIDO E A RELAÇÃO COM AQUELA QUE EXERCE A FUNÇÃO MATERNA
}

\author{
Claudia Petter ${ }^{1}$ \\ Ronalisa Torman ${ }^{2}$
}

\begin{abstract}
Resumo: O presente artigo tem por objetivo verificar se o profissional da Nutrição frente ao paciente que apresenta Obesidade Mórbida possui conhecimento acerca de como se estabelece a relação deste, com aquela que exerce a funçáo materna. Método: A pesquisa foi de natureza qualitativa tendo como instrumento principal um roteiro de entrevista semiestruturada. Para a interpretação dos dados utilizou-se a análise de conteúdo, proposta por (BARDIN, 2011), da qual emergiram duas categorias. Resultados: A amostra foi composta por dez nutricionistas que atendiam ou já haviam atendido pacientes Obesos Mórbidos e que atuavam na região do Vale do Rio dos Sinos e Serra Gaúcha. Constatou-se grande valorizaçáo do trabalho interdisciplinar, pois $100 \%$ das entrevistadas acreditam ser fundamental trabalhar em equipe na medida que atendem pacientes obesos mórbidos. A análise de conteúdo revelou ainda que $80 \%$ das nutricionistas entrevistadas, não possuem conhecimento acerca de como se estabelece a relação do paciente obeso mórbido com aquela que exerce a função materna. Porém todas entrevistadas concordam que uma vez que tivessem esse conhecimento, o mesmo as auxiliaria no atendimento a esses pacientes. Conclusão: Verificou-se que a maioria dos profissionais da nutrição não possui conhecimento acerca de como se estabelece a relação do paciente obeso mórbido com aquela que exerce a função materna e embora trabalhem com pacientes obesos mórbidos, nenhuma das entrevistadas possui curso voltado para obesidade mórbida.
\end{abstract}

Palavras-chave: Função Materna. Interdisciplinariedade. Nutrição. Obesidade Mórbida. Psicologia.

1 Graduada em Nutrição. Universidade Feevale - Novo Hamburgo-RS.

2 Psicóloga. Mestre em Ciências Sociais Aplicadas. Especialista em Psicopedagogia Clínica e Institucional. Coordenadora do Projeto de Extensão - Laços de Vida. Docente e Supervisora Clínica da Universidade Feevale - Novo Hamburgo-RS. 


\title{
THE NUTRITIONIST KNOWLEDGE FRONT THE MORBID OBESE PATIENT AND THE RELATIONSHIP WITH THE ONE WHO EXERCISES THE MATERNAL FUNCTION
}

\begin{abstract}
The objective of this article is to verify if the professional of Nutrition front the patient who presents Morbid Obesity has knowledge about how the relation of this one with the one who exercises the maternal function is established. Method: The research was of qualitative nature having as main instrument a script of semi-structured interview. For the interpretation of the data was used the content analysis, proposed by (BARDIN, 2011), from which emerged two categories. Results: The sample consisted of ten nutritionists who attended or had already attended Morbid Obese Patients and who worked in the Vale do Rio dos Sinos and Serra Gaúcha region. There was great appreciation of interdisciplinary work, since $100 \%$ of the interviewees believe that it is fundamental to work as a team as they treat morbid obese patients. The content analysis also revealed that $80 \%$ of the interviewed nutritionists do not know how to establish the relationship between the morbid obese patient and the one who performs the maternal function. However, all interviewees agreed that once they had this knowledge, it would assist them in the care of these patients. Conclusion: It was verified that the majority of nutrition professionals do not have knowledge about how the morbid obese patient relationship is established with the one that exercises the maternal function and although they work with morbid obese patients, none of the interviewees has a course focused on morbid obesity.
\end{abstract}

Keywords: Maternal Function. Interdisciplinarity. Nutrition. Morbid obesity. Psychology.

\section{INTRODUÇÃO}

A incidência da obesidade tem aumentado consideravelmente nos últimos anos e há um significativo número de pessoas classificadas como obesas mórbidas. Essa patologia alimentar resulta de um balanço energético positivo constante em que a ingestão calórica supera o gasto energético, levando os indivíduos a um índice de massa corporal (IMC) maior ou igual a $40 \mathrm{~kg} / \mathrm{m}^{2}$, também conhecida como obesidade grau III ou severa (COSTA, 2004).

Faz-se necessário que o profissional da nutrição entenda a relação que o sujeito estabelece com o alimento e que o comportamento alimentar se associa a uma série de fatores, não apenas de âmbito nutricional e fisiológico, mas abriga e transmite afetos, dores, carências, vivências da infância, remorsos, dentre tantos outros (VASCONCELOS; SEPULVEDA, 2011).

É coerente pensar na obesidade como uma doença contemporânea, pois numa sociedade de consumo onde a constituição de um corpo ideal e o prazer de comer se conectam justamente pela repressáo alimentar, os desejos passam a girar em torno do que não é permitido (BERG, 2008).

Segundo Oliveira (2006) a obesidade é entendida pela abordagem psicanalítica como sendo o reflexo de algum conflito mãe e filho, no que diz respeito à questão da alimentação deste enquanto bebê. É importante compreender que através da alimentação a criança vincula com a mãe e a partir desse contato que foi estabelecido, é que se construirá a sua relação com o alimento. Quando esta relação 
é constituída de maneira inadequada, o ato de comer passa a ser a única fonte de prazer e recompensa, trazendo assim alívio para as situaçóes difíceis futuramente encontradas.

O autor Dalgalarrondo (2008) ressalta que, o sujeito tende a recorrer à comida como forma de compensação da falta de afeto do qual necessita e que sente que nunca receberá de maneira adequada. Em consequência disso os índividuos têm dificuldade de diferenciar o desejo de se alimentar, ao se depararem com situaçóes indesejáveis, com o simples ato de absorver o alimento de modo mecânico.

A busca por este tema, portanto, surgiu das inquietaçôes que emergiram na pesquisadora no decorrer da graduação em Nutrição, uma vez que a obesidade precisa ser investigada para além da perspectiva física e orgânica e deve ser percebida também sob o ponto de vista psicológico, buscando compreender a relaçáo estabelecida entre o paciente obeso mórbido com aquela que exerce a função materna.

Diante do exposto acima, é possível inferir que se torna imprescindível que o nutricionista frente ao paciente obeso mórbido não se detenha apenas em avaliar os distúrbios nutricionais, mas também outros fatores associados à obesidade, como fatores genéticos, ambientais, econômicos, culturais, psicológicos, dentre outros. Portanto, acredita-se que seja muito importante que este profissional interaja com uma equipe multidisciplinar de áreas distintas, pois, para o sucesso do tratamento dessa patologia alimentar e os fatores de risco associadas à esta, é fundamental diferentes intervençôes.

\section{MÉTODO}

Para atingir o objetivo estabelecido por este estudo, verificou-se se o profissional da Nutrição frente ao paciente que apresenta Obesidade Mórbida possuía conhecimento acerca de como se estabelecia a relação deste, com aquela que exerce a função materna. Optou-se por uma pesquisa de natureza qualitativa tendo como instrumento principal de coleta dos dados, um roteiro de entrevista semiestruturada com perguntas abertas elaboradas pela autora e orientadora do referido projeto de pesquisa. $\mathrm{O}$ roteiro foi composto por cinco questóes consideradas cruciais para os esclarecimentos do estudo, construídas a partir do problema de pesquisa e dos objetivos propostos. A escolha da amostra foi por indicação e atendendo aos critérios de inclusão definidos na pesquisa, as Nutricionistas deveriam estar atendendo ou já terem atendido pacientes obesos mórbidos. Todas concordaram por livre vontade em participar do estudo. $\mathrm{O}$ contato com as participantes foi realizado via telefone e ou pessoalmente. Neste momento foram combinados a data e o local para a aplicação da entrevista.

As entrevistas ocorreram no período de 01 a 15 de setembro de 2017 . O tempo de duração das mesmas foi de aproximadamente 45 minutos e é importante observar que todas foram gravadas em áudio e posteriormente transcritas. 
Para a apreciaçáo dos dados foi utilizada a análise de conteúdo proposta por Bardin (2011), que indica três etapas para sua realização. Em primeiro lugar foi realizada a pré-análise, fazendo uma leitura preliminar do conteúdo e após esta etapa, a segunda foi a organização e sistematização. Na terceira etapa o conteúdo foi analisado e agrupado por categorias delimitadas e os resultados foram interpretados e relacionados à revisão bibliográfica.

Todos os sujeitos participantes do estudo assinaram o termo de consentimento livre e esclarecido. $\mathrm{O}$ projeto da pesquisa foi submetido à avaliação do Comitê de Ética em Pesquisa, da Universidade Feevale, tendo sido aprovado através do CAAE $\mathrm{n}^{\mathrm{o}}$. 71656317.2.0000.5348, e em conformidade com a Resoluçáo do CNS $\mathrm{n}^{\mathrm{o}}$ 466/2012 do Conselho Nacional de Saúde (BRASIL, 2012).

\section{RESULTADOS}

A população deste estudo foi composta por dez Nutricionistas que estavam atendendo ou que já haviam atendido pacientes Obesos Mórbidos e que atuavam na regiáo do Vale do Rio dos Sinos e Serra Gaúcha. Abaixo segue quadro indicando dados acerca das participantes que compuseram a pesquisa.

Quadro 1 - Participantes da pesquisa

\begin{tabular}{|c|c|c|c|c|c|c|c|}
\hline & Sexo & Interdisciplinaridade & Formaçáo & Especializaçáo & $\begin{array}{l}\text { Tempo de } \\
\text { formaçáo }\end{array}$ & $\begin{array}{l}\text { Quantos } \\
\text { Obesos } \\
\text { Mórbidos } \\
\text { atendeu }\end{array}$ & $\begin{array}{l}\text { Curso sobre } \\
\text { Obesidade } \\
\text { Mórbida }\end{array}$ \\
\hline N1 & $\mathrm{F}$ & Psicólogo. & $\begin{array}{l}\text { Graduação em } \\
\text { Nutriçấo }\end{array}$ & Nutrição clínica & 20 anos & 1 & Não \\
\hline N2 & $\mathrm{F}$ & $\begin{array}{c}\text { Psicólogo } \\
\text { Educador físico } \\
\text { Fisioterapeuta. } \\
\end{array}$ & $\begin{array}{l}\text { Graduação em } \\
\text { Nutrição }\end{array}$ & $\begin{array}{l}\text { Nutrição clínica } \\
\text { funcional }\end{array}$ & 13 anos & 3 & Não \\
\hline N3 & $\mathrm{F}$ & $\begin{array}{c}\text { Enfermeiro } \\
\text { Médico } \\
\text { Psicólogo. } \\
\end{array}$ & $\begin{array}{l}\text { Graduação em } \\
\text { Nutrição }\end{array}$ & Nutrição clínica & 1,5 anos & 3 & Não \\
\hline N4 & $\mathrm{F}$ & Psicólogo. & $\begin{array}{l}\text { Graduação em } \\
\text { Nutriçấo }\end{array}$ & $\begin{array}{l}\text { Educação física } \\
\text { e mestrado } \\
\text { em ciência e } \\
\text { tecnologia dos } \\
\text { alimentos }\end{array}$ & 10 anos & 53 & Não \\
\hline N5 & $\mathrm{F}$ & $\begin{array}{c}\text { Psicólogo } \\
\text { Educador físico. }\end{array}$ & $\begin{array}{c}\text { Graduação em } \\
\text { Nutrição } \\
\end{array}$ & $\begin{array}{c}\text { Nutrição clínica e } \\
\text { materno infantil }\end{array}$ & 13 anos & 10 & Não \\
\hline N6 & $\mathrm{F}$ & $\begin{array}{c}\text { Médico } \\
\text { Enfermeiro } \\
\text { Psicólogo. } \\
\end{array}$ & $\begin{array}{l}\text { Graduação em } \\
\text { Nutrição }\end{array}$ & $\begin{array}{l}\text { Saúde da família } \\
\text { e Comunidade } \\
\text { (cursando) }\end{array}$ & 1,5 anos & 5 & Não \\
\hline N7 & $\mathrm{F}$ & $\begin{array}{c}\text { Psicólogo } \\
\text { Educador físico } \\
\text { Médico. } \\
\end{array}$ & $\begin{array}{l}\text { Graduação em } \\
\text { Nutriçáo }\end{array}$ & $\begin{array}{l}\text { Comportamento } \\
\text { alimentar }\end{array}$ & 1,5 anos & 20 & Não \\
\hline N8 & $\mathrm{F}$ & $\begin{array}{c}\text { Médico } \\
\text { Psicólogo. } \\
\end{array}$ & $\begin{array}{c}\text { Graduação em } \\
\text { Nutrição } \\
\end{array}$ & Nutrição esportiva & 4 anos & 10 & Não \\
\hline N9 & $\mathrm{F}$ & $\begin{array}{c}\text { Médica } \\
\text { Psicólogo } \\
\text { Educador físico }\end{array}$ & $\begin{array}{l}\text { Graduação em } \\
\text { Nutrição }\end{array}$ & $\begin{array}{l}\text { Nutrição materno } \\
\text { infantil e Nutrição } \\
\text { na atenção básica. }\end{array}$ & 11 anos & 278 & Não \\
\hline
\end{tabular}




\begin{tabular}{|c|c|c|c|c|c|c|c|}
\hline Sexo & Interdisciplinaridade & Formaçáo & Especializaçáo & $\begin{array}{c}\text { Tempo de } \\
\text { formaçáo }\end{array}$ & $\begin{array}{c}\text { Quantos } \\
\text { Obesos } \\
\text { Mórbidos } \\
\text { atendeu }\end{array}$ & $\begin{array}{c}\text { Curso sobre } \\
\text { Obesidade } \\
\text { Mórbida }\end{array}$ \\
\hline N10 & $\mathrm{F}$ & $\begin{array}{c}\text { Psicólogo } \\
\text { Fonoaudiólogo } \\
\text { Assistente social. }\end{array}$ & $\begin{array}{c}\text { Graduação em } \\
\text { Nutrição }\end{array}$ & $\begin{array}{c}\text { Cursando } \\
\text { residência } \\
\text { multiprofissional }\end{array}$ & $\begin{array}{c}1 \text { ano e } 9 \\
\text { meses }\end{array}$ & 50 & Não \\
\hline
\end{tabular}

Fonte: Dados da pesquisa

Ao término deste estudo emergiram duas categorias a partir da análise e discussão das entrevistas, sendo que a primeira foi denominada de "a nutrição no contexto de uma clínica interdisciplinar com paciente obeso mórbido". Entre as dez entrevistadas na pesquisa de campo, todas concordaram que o trabalho interdisciplinar é fundamental no manejo com pacientes obesos mórbidos. Apontaram que a articulação entre diferentes saberes somente traz benefícios, maior adesão e resultados mais satisfatórios para todos envolvidos no processo. Todas as entrevistadas possuem algum tipo de Especializaçáo como, por exemplo, em Comportamento Alimentar, Alimentação e Nutrição na Atenção Básica, Nutrição Clinica Funcional. Identificou-se que embora todas tenham concordado sobre a importância de ter uma formação voltada para obesidade mórbida, nenhuma possui algum curso especifico nesse sentido.

A segunda categoria que emana dos resultados da pesquisa foi denominada "o conhecimento do nutricionista sobre a relação do obeso mórbido com aquela que exerce a funçáo materna e os desdobramentos desse saber no atendimento a esse paciente". Nesta fica evidente que $80 \%$ das Nutricionistas entrevistadas, não possuem conhecimento acerca de como se estabelece a relação do paciente obeso mórbido com aquela que exerce a função materna. Porém, todas entrevistadas concordam que uma vez que tivessem esse conhecimento, o mesmo as beneficiaria no atendimento a esses pacientes.

Portanto, verificou-se que as duas categorias que emergiram da pesquisa de campo confirmaram o que fora levantado incialmente pela hipótese de pesquisa.

Salienta-se que muito embora a amostra não corresponda significativamente à população totalitária a ser investigada na região do Vale do Rio dos Sinos e Serra Gaúcha/RS, ela objetiva a compreensão no discurso a respeito do profissional da Nutrição possuir conhecimento acerca de como se estabelece a relaçáo do paciente obeso mórbido com aquela que exerce a função materna. Os resultados foram analisados a partir da revisão teórica, contemplando autores clássicos e contemporâneos que fundamentam o objeto de estudo da pesquisa.

Embora os resultados apresentados sejam relevantes, eles devem ser observados com parcimônia. Trata-se de uma amostra não probabilística, portanto, estes dados não podem ser generalizados. Trata-se de dados confiáveis e reveladores sobre o grupo avaliado e não da população dos profissionais da nutrição na sua totalidade. 


\section{DISCUSSÁO}

Foram entrevistadas 10 nutricionistas que estavam atendendo ou já haviam atendido pacientes obesos mórbidos respondendo assim ao problema de pesquisa, uma vez que identifica se o profissional da Nutrição frente ao paciente que apresenta Obesidade Mórbida possui conhecimento acerca de como se estabelece a relação deste com aquela que exerce a função materna. As nutricionistas participantes da pesquisa estaráo identificadas como $\mathrm{N} 1$ até N10, ou seja, primeira a décima nutricionista entrevistada.

Sendo assim, através das entrevistas realizadas emergiram duas categorias de análise que possibilitaram a discussão e que serão apresentadas a seguir. As duas categorias foram nomeadas da seguinte maneira: "a nutrição no contexto de uma clínica interdisciplinar com paciente obeso mórbido" e "o conhecimento do nutricionista sobre a relação do obeso mórbido com aquela que exerce a função materna e os desdobramentos desse saber no atendimento a esse paciente". $\mathrm{Na}$ primeira categoria ficou evidente a importância do trabalho em equipe junto a pacientes obesos mórbidos tendo reconhecimento unânime entre as dez nutricionistas entrevistadas, o que corrobora com os achados dos autores Rodrigues e Seidl, (2015) quando assinalam, obesidade é uma doença complexa e é fundamental que seja vista através de diferentes olhares. Por ser considerada multifatorial, exige um tratamento que ofereça diferentes abordagens. Essa realidade coloca de forma contundente, mais uma vez, a necessidade de um enfoque com vários profissionais na atenção e cuidado a estes pacientes, valorizando aspectos físicos, psicológicos e sociais. Fato que fica evidente nas falas apresentadas a seguir:

Sim é fundamental trabalhar em equipe porque não é só a comida o problema né, acho que a comida é um, o excesso do peso é uma consequência, independente de ser mórbido ou náo acho que toda obesidade tem a ver com o emocional mesmo que seja fisiológico. (ENTREVISTADA N1).

Sim porque seria interessante ah um acompanhamento psicológico para né avaliar a questão do comer emocional ah também um atendimento clinico assim médico pra descartar algum problema hormonal né ou outra doença que esteja dificultando a perda de peso desse paciente um educador físico né pra que ele pudesse realizar uma atividade física a maioria deles não realiza atividade física porque já tem comprometimento nas articulaçóes, aí não podem caminhar porque já estão comprometidos né isso limita mais ainda a perda é a perda de peso nesse tratamento ah enfim o que me ocorre agora entre outros profissionais que poderiam auxiliar. (ENTREVISTADA N7).

Os autores Borges, Sampaio e Gurgel (2012) ressaltam que na atual conjectura de sociedade, da contemporaneidade, da globalização, onde tudo se renova, transforma e modifica muito rapidamente é necessário pensar o trabalho interdisciplinar como estratégia alcançável e desejável, pois a integração dos saberes viabiliza o desenvolvimento de açóes conjuntas para acompanhar todo esse desenvolvimento e para um melhor entendimento desses sujeitos cada vez mais complexos. 
Foi interessante perceber que em relação a este aspecto todas as entrevistadas concordaram com a necessidade e importância de trabalhar compartilhando saberes. $\mathrm{O}$ trabalho em equipe propicia uma visão mais integral do sujeito, o que leva a maior adesão ao tratamento e resultados satisfatórios, como verifica-se nos recortes das falas de duas entrevistadas.

Com certeza, eu acho fundamental ter uma equipe interdisciplinar não só para esses, mas para os outros também né a gente sempre nota que o resultado é muito melhor quando a gente trabalha o paciente como um todo e não só alimentação né. (ENTREVISTADA N5).

Notei também que havia uma falta de adesão ainda percebo que é difícil tu motivar um obeso mórbido a seguir até o fim, mas aí justamente o trabalho interdisciplinar é o que faz a diferença porque quando ele vai tentar desistir da nutrição tem que ter outro profissional que de outro enfoque pra que ele continue no tratamento. (ENTREVISTADA N4).

O Ministério da Saúde (BRASIL, 2014) salienta que o cuidado com o obeso extrapola o campo da saúde, sinalizando a necessidade de articulaçáo entre diferentes saberes para prevençáo e controle do aumento de excessivo de peso, uma vez que o profissional sozinho, considerando toda sua capacidade e experiência, náo consegue abarcar toda a pluridimensionalidade do ser humano, fazendo-se necessário o trabalho em equipe. Em concordância com a frase acima, duas nutricionistas discorrem a este respeito:.

Sim, porque não é só uma questão alimentar e de escolha alimentar que vai fazer com que ele seja um obeso daqui a pouco não é nem uma questão alimentar né é uma questão psicológica, então tu poder envolver o médico que vai atender ele pensando na saúde coletiva, a enfermeira também para envolver ela nesse cuidado, psicólogo eu vejo que é essencial, porque como eu falei às vezes não é uma questão alimentar especifica e o nutricionista por si só não consegue resolver ele precisa de outro profissional pra ter também esse olhar diferente sobre esse paciente o nutricionista por si só não consegue resolver. (ENTREVISTADA N6).

Com toda certeza a gente trabalha aqui com a equipe ATO, que é a equipe de Apoio ao Tratamento da Obesidade, então essa equipe é composta por: uma nutricionista (no caso eu), uma psicóloga um educador físico e uma médica clinica né entâo a gente faz esses atendimentos sempre de forma interdisciplinar. (ENTREVISTADA N9).

Frente a vários âmbitos e perante o processo de especialização do conhecimento e intervençóes acerca destes sujeitos complexos, o trabalho em equipe surge como estratégia para promover a qualidade dos serviços. A importância da equipe se dá pelo fato de ser preciso desenvolver um trabalho conjunto no qual todos os profissionais se envolvam, de acordo com seu nível de competência, para assim, poder formar um saber capaz de dar conta da complexidade dos problemas que abarcam esse ser (CARDOSO; HENNINGTON, 2011).

Corroborando com os autores acima, apresenta-se um recorte da fala de uma das nutricionistas: 
Sim é bem importante, aham, porque tem a parte psicológica que é bem importante questão, acho que tem que ter atividade física, entáo educador físico, às vezes até fisioterapeuta também né, eu acho que eles precisam de uma equipe apoiando. (ENTREVISTADA N2).

Nesta categoria constatou-se grande valorização do trabalho em equipe para se obter uma compreensáo mais ampla, integral dos sujeitos, sendo considerado essencial pelas entrevistadas. Afirmam que o trabalho interdisciplinar possibilita benefícios aos pacientes e a todos envolvidos no processo.

Já no que tange a discussão do que emergiu na segunda categoria apresentada anteriormente, expõem-se os dados colhidos: entre as dez entrevistadas duas afirmaram ter conhecimento teórico sobre a relação do obeso mórbido com sua mãe e oito afirmaram não ter, porém todas entrevistadas concordam que uma vez que se apropriassem deste saber, auxiliaria no atendimento desses pacientes.

A alimentação, por ser um momento de interação da díade mãe-bebê, faz parte da experiência de formação do indivíduo, pois não se trata apenas da satisfação das necessidades biológicas, mas começa neste momento a ser estabelecida a noção de saciedade e interrupçáo dos estímulos da fome, além da sensação prazerosa provocada pelo contato corporal mãe-bebê e todos os estímulos presentes no ato de amamentar. Entáo na fase adulta, pode-se pensar que esses momentos que são constitutivos, podem ser revivenciados em um momento de angústia, pois o sujeito tende a buscar solução para situações de conflito através de recursos já conhecidos e vivenciados, sejam eles agradáveis ou não (GROMOWSKI, 2016).

Ainda conforme autores acima citados, o corpo segundo a psicanálise não corresponde somente ao corpo biológico, ou seja, juntamente com o crescimento físico, o investimento no desenvolvimento afetivo deve existir. Inicialmente o corpo é investido libidinalmente pela mãe e mais tarde, pelo próprio sujeito. $\mathrm{Na}$ falta de investimento libidinal, a experiência do corpo fica ligada a necessidade. É essencial um desempenho adequado da função materna para que o sujeito possa se constituir.

$\mathrm{O}$ ato de alimentar-se traz à tona distintas sensações e remete o sujeito ao momento em que este era alimentado pela sua mãe. Lembranças do afeto, aconchego e a segurança proporcionada por essa interação mãe-filho e onde suas necessidades eram supridas, um momento, portanto, onde afeto e comida se combinam. Assim sendo, alimentar-se de forma compulsiva demonstra a dificuldade do sujeito em lidar com os seus sentimentos, emoçóes e frustraçóes, cuja origem está na infância e na relação mãe-bebê (FERREIRA; MEIER, 2004).

A mãe que compreende as demandas nutricionais do seu filho e as distingue das outras necessidades, permite que a criança consiga diferenciar a sensaçáo de fome de outras emoçóes. Uma vez que, esta que exerce a função materna, não consegue interpretar corretamente os sinais do seu filho, faz com que este ao crescer não consiga distinguir quando está com fome e saciado, de outras sensaçôes que o alimento náo consegue suprir, entáo o sujeito - obeso, oculta o vazio interior com excesso de alimento (VASCONCELOS; SEPULVEDA, 2011). 
A seguir, apresentam-se recortes das entrevistadas, que estáo em concordância com os autores acima:

Sim com certeza, a relação materna e as referências desse paciente interferem, mas nunca especificamente li algo sobre obesidade mórbida IMC acima ligado com a questão materna, mas com certeza interfere, não tenho dúvidas disso. (ENTREVISTADA N9).

Sim, tanto quando a relação é bem desenvolvida como quando não é, [...] também quando se percebe que tem um vinculo assim bem tenue, aí os transtornos acontecem. É durante a reflexão na hora da consulta né, então, geralmente ou são mães que muitas vezes não tinham o que comer em casa $\mathrm{e}$ depois quando esses filhos viram adultos, começam a trabalhar, a ter acesso ao dinheiro e a comida, depois casam e não deixam faltar nada em casa. Então os armarios ficam sempre abarrotados de coisas né, então eu acredito que tem relação com as mães que sempre ofereciam demais, faziam com que a criança comece de tudo, que faziam grande quantidade de comida, grandes variedades e faziam com que a criança comece tudo que tinha no prato. (ENTREVISTADA N8).

Corroborando com a hipótese de pesquisa levantada nesse estudo, a discussão aponta que apenas $20 \%$ das nutricionistas entrevistadas possuem conhecimento acerca de como se estabelece a relaçáo do paciente obeso mórbido, com aquela que exerce a função materna.

Todas as entrevistadas, ou seja, $100 \%$ delas concordam que uma vez que tivessem conhecimento acerca de como se estabelece a relação do obeso mórbido com aquela que exerce a função materna, este auxiliaria ao atendimento aos seus pacientes. As falas a seguir, evidenciam este dado:

Eu acho que sim, acho que é meio um divisor de águas assim, possibilita o nutricionista ter outro olhar e outro manejo, outro tipo de atendimento de conduta com esse paciente né. (ENTREVISTADA N2).

Com certeza, com certeza porque qualifica tua escuta também né com toda certeza. (ENTREVISTADA N9).

Acho que sim, acho sim é importânte a gente identificar o porquê do desenvolvimento dessa da obesidade né a função materna é um deles então sim. Daí a gente ter esse olhar um pouco voltado para isso no adulto acaba pelo menos eu acabo náo tendo. (ENTREVISTADA N6).

Nesse sentido Martta (2002) relata em se tratando de obesidade mórbida, temos que refletir sobre o que aconteceu na vida do sujeito para que essa patologia se estabelecesse.

Os autores Gonzales e Branco (2003) assinalam que os nutricionistas, assim como os demais profissionais da saúde, possuem ferramentas valiosas para lidar com os pacientes, capazes de promover resultados surpreendentes sobre algumas doenças e tratamentos. Sendo assim, legitimando a fala dos autores acima mencionados e através da análise de conteúdo realizada nesta pesquisa, foi possível verificar que mediante uma proposta de dieta ou conduta alimentar, o bom senso é indispensável 
para que seja capaz de contrapor inúmeras possibilidades e técnicas que se apresentam sem jamais perder de vista o horizonte dos desejos, preferências e intençóes do paciente. Importante frisar que verificou-se que há escassas publicaçóes sobre o objeto de estudo da presente pesquisa no campo de conhecimento da Nutrição.

\section{CONCLUSÁO}

Torna-se importante mencionar que através da pesquisa bibliográfica realizada, foi possível verificar a importância da relação daquela que exerce a função materna na construção da subjetividade do sujeito e na contribuição do comportamento alimentar deste. Fica evidente também, através dos autores pesquisados, o quanto é importante e mesmo crucial para a saúde e desenvolvimento do bebê, ter uma relação saudável com os alimentos. O processo alimentar é um dos alicerces da vida emocional nos primórdios da infância, é o eixo do universo da criança e o descontentamento e a gratificaçáo estáo intimamente associados a várias patologias, dentre elas, a obesidade mórbida.

Observa-se que embora os dados encontrados nesta pesquisa sejam promissores, é altamente recomendável que distintos estudos, com outras amostras sejam realizados, buscando relacionar o tema com outros tipos de variáveis, que por sua vez, não foram contempladas neste estudo.

Portanto e para finalizar, vale destacar que este artigo tem o intuito de contribuir com uma nova ótica para os profissionais da Nutrição, ampliando questionamentos e instigando-os em direção a este tema pouco aprofundado, para a produção de outras pesquisas acerca do assunto. Ressalta-se que há o veemente desejo de que esta venha a contribuir com a área da Nutrição, expandindo novos horizontes, possibilitando aos profissionais e aspirantes desse segmento, uma maior sensibilidade, abertura e entendimento para o novo.

\section{REFERÊNCIAS}

BARDIN, L. Análise de Conteúdo: edição revista e ampliada. 1. ed. São Paulo, SP: Almedina Brasil, 2011.

BERG, Raquel. Uma análise freudiana da obesidade. Dissertação (Mestrado em Psicologia Escolar e do Desenvolvimento Humano) - Instituto de Psicologia, Universidade de São Paulo, São Paulo. 2008. doi: 10.11606/D.47.2008.tde-05062008-111148. Disponível em: <http://www.teses.usp.br/teses/disponiveis/47/47131/tde-05062008111148/pt-br.php. Acesso em: 9 de abr. 2017.

BORGES, Maria J. Lopes, SAMPAIO, Aletheia Soares, GURGEL, Idê G. Dantas. Trabalho em equipe e interdisciplinaridade: desafios para a efetivação da integralidade na assistência ambulatorial às pessoas vivendo com HIV/Aids em Pernambuco. Ciência \& Saúde Coletiva, 17(1):147-156, 2012. Disponível em: <http://www.scielo.br/pdf/csc/ v17n1/a17v17n1>. Acesso em: 13 abr. 2017 
BRASIL. Ministério da Saúde. Conselho Nacional de Saúde. Comissão Nacional de Ética em Pesquisa. RESOLUÇÃO no 466/12 versão 2012. Disponível em: < http://www.pppg. ufma.br/uploads/files/Reslucao\%2046612.pdf>. Acesso em: 15 abr. 2017.

BRASIL. Ministério Da Saúde. Perspectivas e desafios no cuidado às pessoas com obesidade no SUS: resultados do Laboratório de Inovação no manejo da obesidade nas Redes de Atenção à Saúde. Organização Pan-Americana da Saúde. Brasília: Ministério da Saúde, 2014.

CARDOSO, Cíntia Garcia, HENNINGTON, Élida Azevedo. Trabalho em equipe e reunióes multiprofissionais de saúde: uma construção à espera pelos sujeitos da mudança. Trab. educ. saúde (Online), Rio de Janeiro, v. 9, supl. 1, p. 85-112, 2011. Disponível em: <http://www.scielo.br/scielo.php?script=sci_arttext\&pid=S1981$77462011000400005 \& \operatorname{lng}=$ en $\&$ nrm=iso $>$. Acesso em: 10 de maio, 2017.

COSTA, R. F. Obesidade: Exercício Físico. Revista Qualidade em Alimentação Nutrição. n. 17, 10-11. Janeiro 2004.

DALGALARRONDO, P. Psicopatologia e semiologia dos transtornos mentais. Porto Alegre: Artmed, 2008.

FERREIRA, Maria Marta; MEIER, Marcos. Psicologia do emagrecimento. Rio de Janeiro, RJ: Revinter, 2004. 136 p.

GONZALES, R.F.; BRANCO, R. A relação com o paciente: teoria, ensino e prática. Rio de Janeiro, RJ: Guanabara Koogan, 2003.

GROMOWSKI, Alessandra Elisa et al. Significados atribuídos ao comer em mulheres obesas que participaram de um programa para redução de peso. Rev. SPAGESP, Ribeirão Preto, v. 17, n. 1, p. 110-123, 2016. Disponível em: <http://pepsic.bvsalud.org/scielo. php?script=sci_arttext $\&$ pid $=\$ 1677-29702016000100010 \& \operatorname{lng}=$ pt $\& n r m=i s o>$. Acesso em: 6 de maio, 2017.

MARTTA, Alessandra Kuhn. Pensando sobre obesidade mórbida. Correio da APPOA, Porto Alegre, n. 106, set. 2002.

OliveIRA, J. H. A. Aspectos Psicológicos de Obesos Grau III Antes e Depois da Cirurgia Bariátrica. Tese de Doutorado. Curso de Pós-Graduação e Psicologia do Centro de Ciências da Vida, Pontifícia Universidade Católica de Campinas. 2006. Campinas, São Paulo. PP. Xxii + 175 .

RODRIGUES, Marcela Abreu, SEIDL Eliane Maria Fleury. Apoio Social e Reganho de Peso Pós-Cirurgia Bariátrica: Estudo de Caso sobre Intervenção com Cuidador. Temas em Psicologia. Vol. 23, no 4, 2015.

VASCONCELLOS, Sheyna Cruz; SEPULVEDA, Karine Rodrigues. Obesidade mórbida: um corpo em evidência e em desamparo. Rev. SBPH, Rio de Janeiro, v. 14, n. 1, p. 92-111, jun. 2011. Disponível em: <http://pepsic.bvsalud.org/scielo.php?script=sci_ arttext\&pid=S1516-08582011000100006\&lng=pt\&nrm=iso >. Acesso em: 21 abr. 2017. 